\title{
Sevoflurano tópico en infección superficial por SARM tras artroplastia de rodilla. Caso Clínico
}

\section{Topical Sevoflurane for Superficial MRSA Infection after Knee Arthroplasty. Case Report}

\author{
Ainara Achaerandio-de Nova ${ }^{1(1)}$ Sergio Losa-Palacios ${ }^{1([)}$ Alfredo San Martín-Martínez ${ }^{10}$ \\ Manuel Gerónimo-Pardo ${ }^{10}$
}

${ }^{1}$ Complejo Hospitalario Universitario de Albacete, Albacete, Albacete, España

Rev Chil Ortop Traumatol 2020;61:83-89.
Address for correspondence Manuel Gerónimo-Pardo, PhD, Departamento de Anestesiología, Complejo Hospitalario Universitario de Albacete, Hermanos Falcó 37, Albacete, Albacete 02002, España (e-mail: sergepu@hotmail.com).

\section{Resumen \\ Palabras clave \\ - artroplastia de reemplazo de rodilla \\ - infección de la herida quirúrgica \\ - staphylococcus aureus resistente a meticilina \\ - tratamiento conservador \\ - sevoflurano}

\section{Abstract}

received

December 14, 2019

accepted

June 19, 2020
Intentar el tratamiento retentivo de material protésico ante heridas quirúrgicas infectadas por gérmenes resistentes es objeto de debate, especialmente cuando el agente causal es un Staphylococcus aureus resistente a meticilina (SARM). Una paciente diabética y con obesidad tipo I sufrió infección de la herida quirúrgica tras artroplastia de rodilla que no evolucionó bien con antibioterapia empírica y terapia hiperosmolar. Se planificó una reintervención que fue demorada por motivos extramédicos (falta de terapia de presión negativa para cubrir la herida postoperatoria, pues se preveía no poder realizar cierre primario). Mientras se conseguía este material, y tras obtener el consentimiento de la paciente, se iniciaron irrigaciones de la herida con sevoflurano tópico off-label, pues ese fármaco ha mostrado capacidad antimicrobiana. La evolución clínica fue excelente desde el inicio a pesar de que en el cultivo se aisló un SARM resistente a la antibioterapia empírica, por lo que se desestimó la reintervención y se continuó con sevoflurano tópico junto a la antibioterapia dirigida por antibiograma, lográndose la curación completa de la herida tras 6 semanas. Durante ese tiempo, la paciente no experimentó ningún efecto adverso atribuible al sevoflurano. El sevoflurano tópico aparece como una valiosa nueva opción terapéutica ante heridas postoperatorias infectadas, especialmente cuando los gérmenes causantes son resistentes a los antibióticos convencionales.

It is challenging to try a retentive treatment of prosthetic material superinfected by resistant microorganisms, especially when the causative agent is a methicillin-resistant Staphylococcus aureus (MRSA). A diabetic, obese female patient suffered from a postoperative wound infection after a knee arthroplasty. Initial treatment with antibiotics and hyperosmolar therapy failed and clinical evolution was no good. Surgery was scheduled, but it was delayed due to nonmedical reasons (lack of negative-pressure therapy to cover the wound since primary wound closure was anticipated to be very improbable to perform). While waiting for this therapy, offlabel irrigations with topical sevoflurane were started after obtaining written consent, 


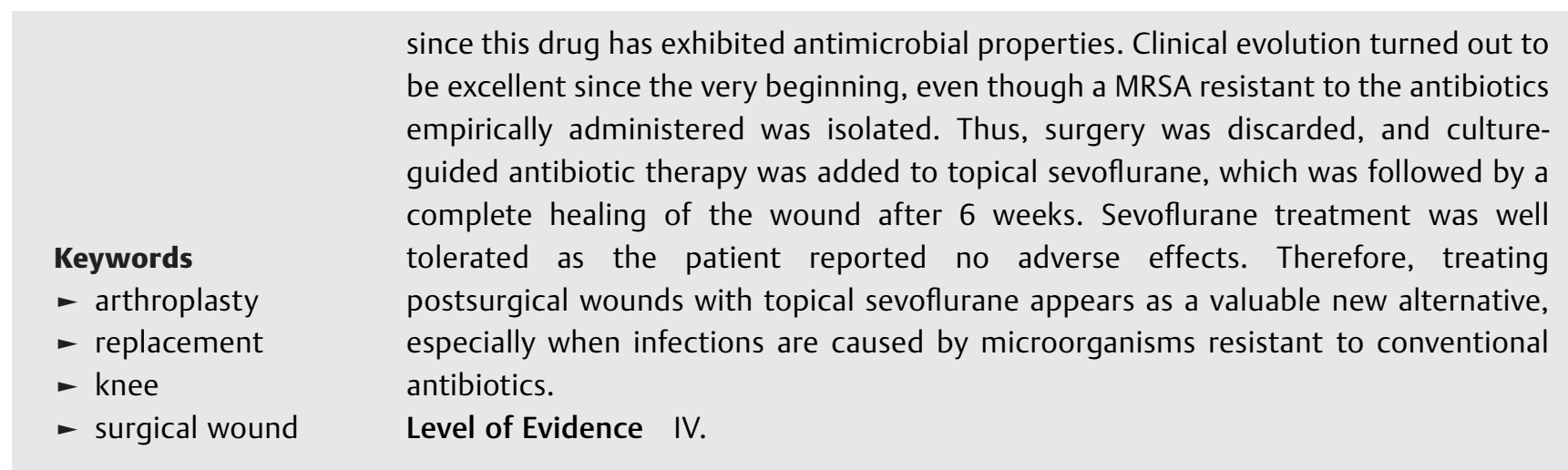

\section{Introducción}

Las infecciones periprotésicas agudas (IPA) o crónicas (IPC), son una de las complicaciones más temibles asociadas a una artroplastia, con alta morbimortalidad y coste económico. El tratamiento de las IPA se basa en desbridamiento quirúrgico, antibioterapia intravenosa y recambio del polietileno (DAIR). ${ }^{1}$ En caso de fracaso (o ante IPC) se realiza un tratamiento más agresivo consistente en recambio protésico en uno o dos tiempos asociado a la antibioterapia intravenosa y oral prolongadas.

Las infecciones de la herida quirúrgica, tanto superficiales como profundas, también pueden aparecer como complicación postoperatoria. En ocasiones, el diagnóstico diferencial entre ellas y la IPA es difícil, y no existe ninguna prueba clínica no invasiva, de laboratorio o de imagen que por sí misma permita diferenciarlas con certeza. ${ }^{2}$ Ese reto diagnóstico aumenta en pacientes con factores de riesgo que interfieren con el proceso normal de cicatrización de heridas (diabetes, hipertensión, obesidad, patología cardiovascular...).

La actitud terapéutica a seguir ante esas infecciones, también puede estar condicionada por motivos extramédicos. Por ejemplo, cuando la falta de material impide la realización del tratamiento elegido.

Presentamos el caso de una paciente intervenida de artroplastia de rodilla que sufrió infección aguda de la herida quirúrgica en la que la actuación planeada se vio interferida por la falta de material disponible, y cómo dicha infección fue inicialmente controlada satisfactoriamente con la aplicación novedosa de sevoflurano tópico.

\section{Caso Clínico}

La paciente era una mujer de 74 años de edad con antecedentes de diabetes, obesidad (IMC 33,2), linfedema en miembros inferiores, alergia a penicilinas y estreptomicina, y portadora de artroplastia de rodilla derecha.

Fue intervenida de artroplastia de rodilla izquierda porque tras tres años de tratamiento conservador, el dolor iba en aumento y las caídas eran frecuentes. El postoperatorio inmediato transcurrió sin incidencias, y la paciente fue dada de alta a los 3 días con curas por enfermería con povidona yodada cada $48-72 \mathrm{~h}$ hasta la retirada de las grapas a las dos semanas por cicatrización completa.
Sin embargo, en la revisión al mes, la herida presentaba dos áreas de necrosis cutánea en las zonas media y distal, eritema y/o celulitis perilesional y un exudado escaso de aspecto seropurulento, cuya muestra se remitió a microbiología. La paciente se encontraba afebril, con una movilidad normal y con derrame intraarticular escaso. En espera de los resultados microbiológicos y analíticos (reactantes de fase aguda), se planteó como diagnóstico diferencial una IPA frente a una infección superficial/profunda de la herida quirúrgica en una paciente con factores de riesgo para sufrir retardo de la cicatrización. Se valoró realizar una artrocentesis pero, dada la celulitis existente, realizarla conllevaría un riesgo elevado de diseminar una eventual infección superficial al espacio intraarticular. En espera de los resultados analíticos y del cultivo, se pautó antibioterapia empírica oral (ciprofloxacino $750 \mathrm{mg} / 12 \mathrm{~h}$ y rifampicina $600 \mathrm{mg} / 24 \mathrm{~h}$ ), curas locales ambulatorias con terapia hiperosmolar ${ }^{3}$ y revisiones diarias.

Al segundo día no se apreciaba mejoría de la herida, y la proteína C reactiva era de $90 \mathrm{mg} / \mathrm{L}$, por lo que se decidió el ingreso hospitalario para realizar DAIR combinado con antibioterapia intravenosa con levofloxacino (500mg/8h) y rifampicina (600mg/24h).

Por temor a no poder realizar un cierre primario de la herida tras el desbridamiento, se solicitó un dispositivo de terapia de presión negativa (TPN) para cubrirla en el postoperatorio inmediato, ${ }^{4,5}$ pero ese dispositivo debía ser aprobado por el seguro médico de la paciente y su empresa nos anticipó que su entrega se demoraría una semana, por lo que se decidió posponer la cirugía hasta entonces. Mientras tanto, la paciente aceptó ser tratada con irrigaciones de sevoflurano empleado fuera de indicación tras ser convenientemente informada. El tratamiento consistió en lavar con suero la herida y, tras dejarla secar, cubrirla con un plástico adhesivo estéril para crear una cámara cerrada (que evitase la volatilización ambiental del fármaco) donde inyectar $5 \mathrm{~mL}$ de sevoflurano (-Figura 1); tras 5-10 minutos, se aspiraba el eventual sevoflurano remanente. Ese procedimiento se realizó diariamente mientras la herida permaneció abierta.

Cuatro días después fue aislado un Staphylococcus aureus resistente a meticilina (MRSA) y a la antibioterapia empírica empleada hasta ahora, que fue sustituida por linezolid (600mg/12h iv). Sin embargo, desde el inicio del tratamiento con sevoflurano la herida había evolucionado muy favorablemente $\mathrm{y}$, para cuando se recibieron los 


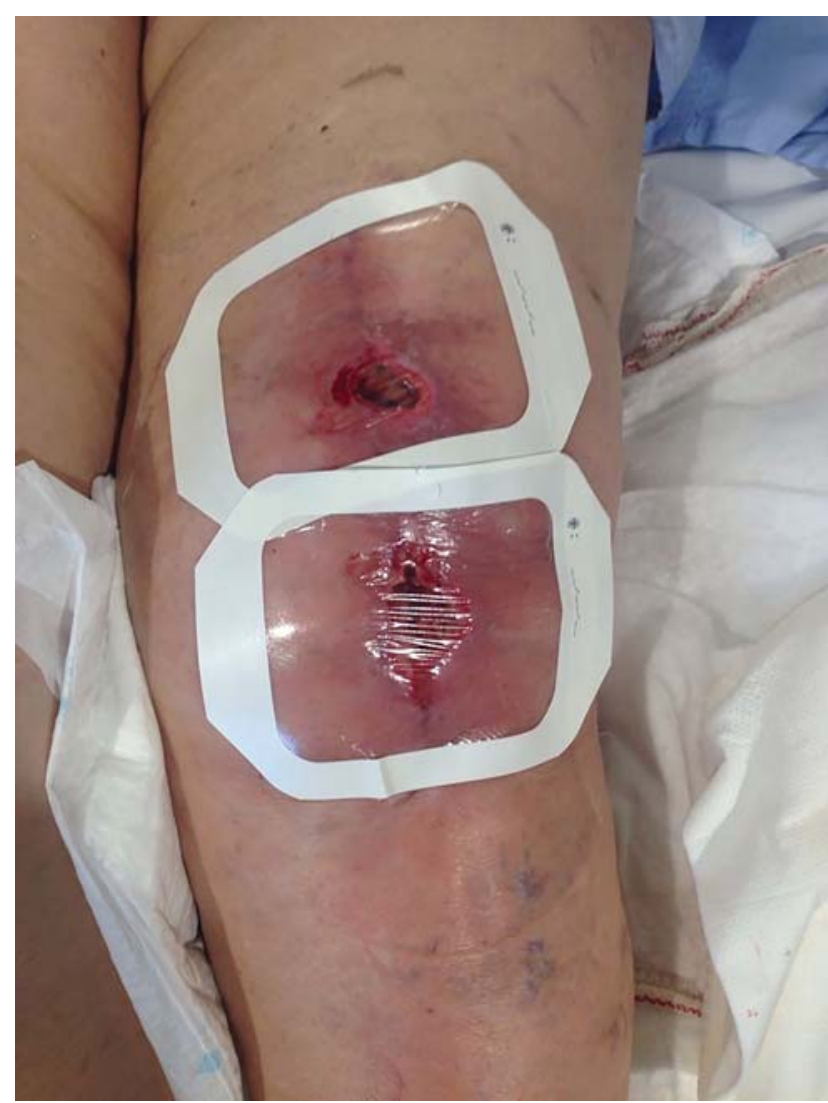

Fig. 1 Heridas cubiertas con plástico adhesivo estéril en el momento previo a la primera irrigación con sevoflurano tópico. Se aprecia la dehiscencia de sutura y el eritema perilesional.

resultados microbiológicos, la celulitis perilesional había desaparecido y el tamaño de la herida se había reducido ( - Figura 2 a y b). Además, la paciente era capaz de caminar y hacer su tratamiento rehabilitador con dolor tolerable. Por ello se pospuso realizar la cirugía unos días en espera de la evolución de la herida y de la PCR.

La evolución clínica continuó siendo favorable, y los reactantes de fase aguda fueron normalizándose gradualmente hasta ser normales a partir de la tercera semana de tratamiento (PCR 5mg/L). La herida fue gradualmente granulando y epitelizando (-Figura $3 \mathbf{a}$ y b), y cicatrizó a las 6 semanas del inicio del tratamiento con sevoflurano ( - Figura 4). El balance articular desde entonces fue completo $\left(0 / 95^{\circ}\right)$ y se ha mantenido a lo largo del seguimiento (-Figuras 5 y $\mathbf{6}$ ). La paciente nunca presentó síntomas locales ni sistémicos sugerentes de ser efectos adversos causados por el sevoflurano. Durante ese tiempo, no se realizaron más cultivos microbiológicos por falta de exudado para tomar muestras.

$\mathrm{Al}$ alta se pautó trimetoprim/sulfametoxazol oral (160/800mg/12h) durante 5 meses. Desde entonces el seguimiento en consulta fue el habitual para cualquier artroplastia $^{6}$ y en la última revisión, realizada tres años después, la paciente continuaba asintomática, con buena movilidad y estabilidad y sin alteraciones analíticas sugerentes de infección.

\section{Discusión}

Las muestras para cultivo tomadas de exudados de heridas quirúrgicas pueden estar contaminadas por flora comensal cutánea que no se comporta como patógena, ${ }^{7}$ especialmente si la muestra se toma con torunda. En nuestro caso consideramos que el SARM era causante de la infección de la herida porque la muestra se tomó mediante aspiración con jeringa y porque no se detectaron otros microorganismos contaminantes.
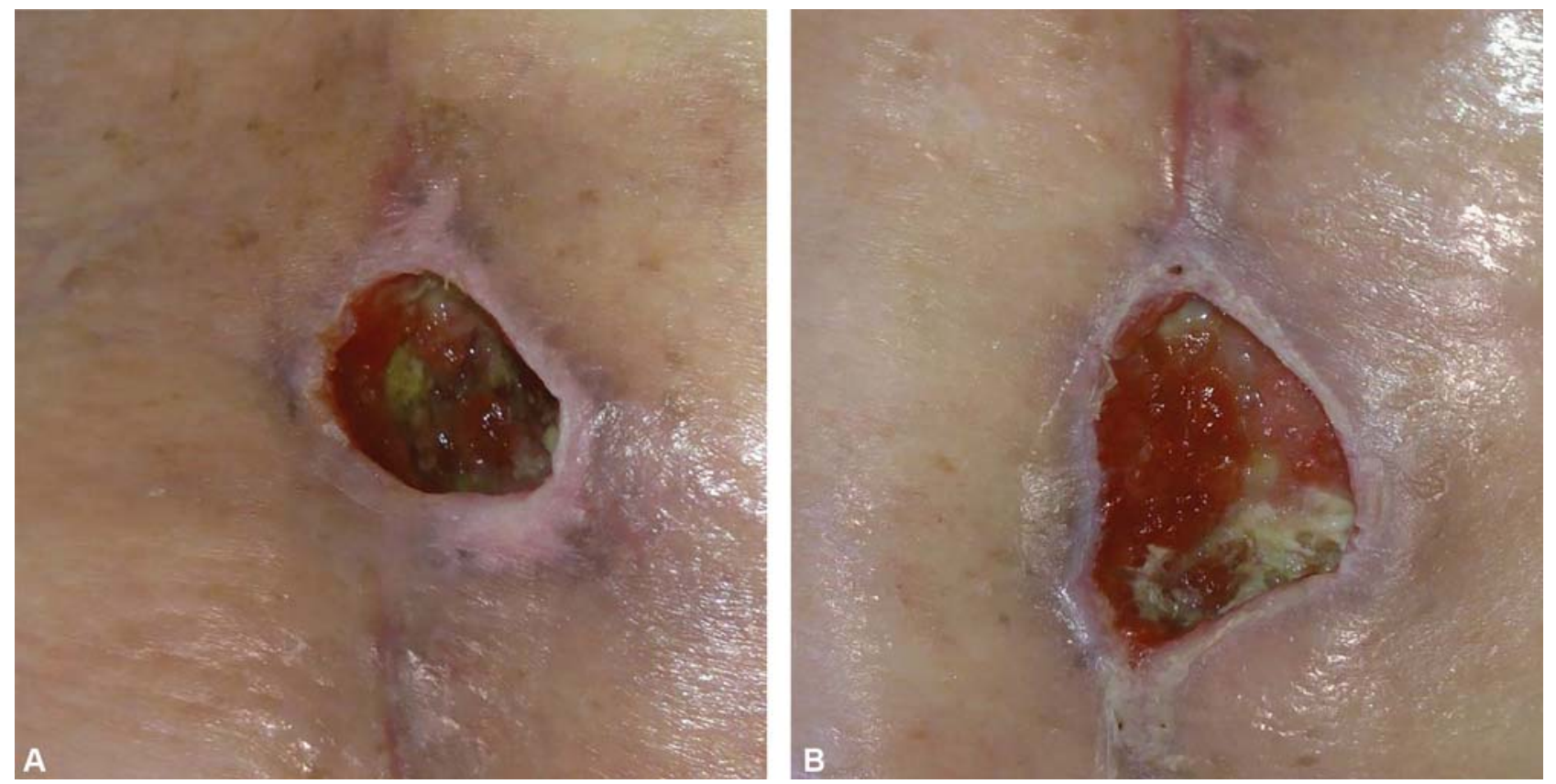

Fig. 2 Detalle de las heridas en zona media (A) y distal (B). Se aprecia la desaparición del eritema perilesional, y el fondo de las heridas aparece limpio, con tejido de granulación y escasa fibrina. 


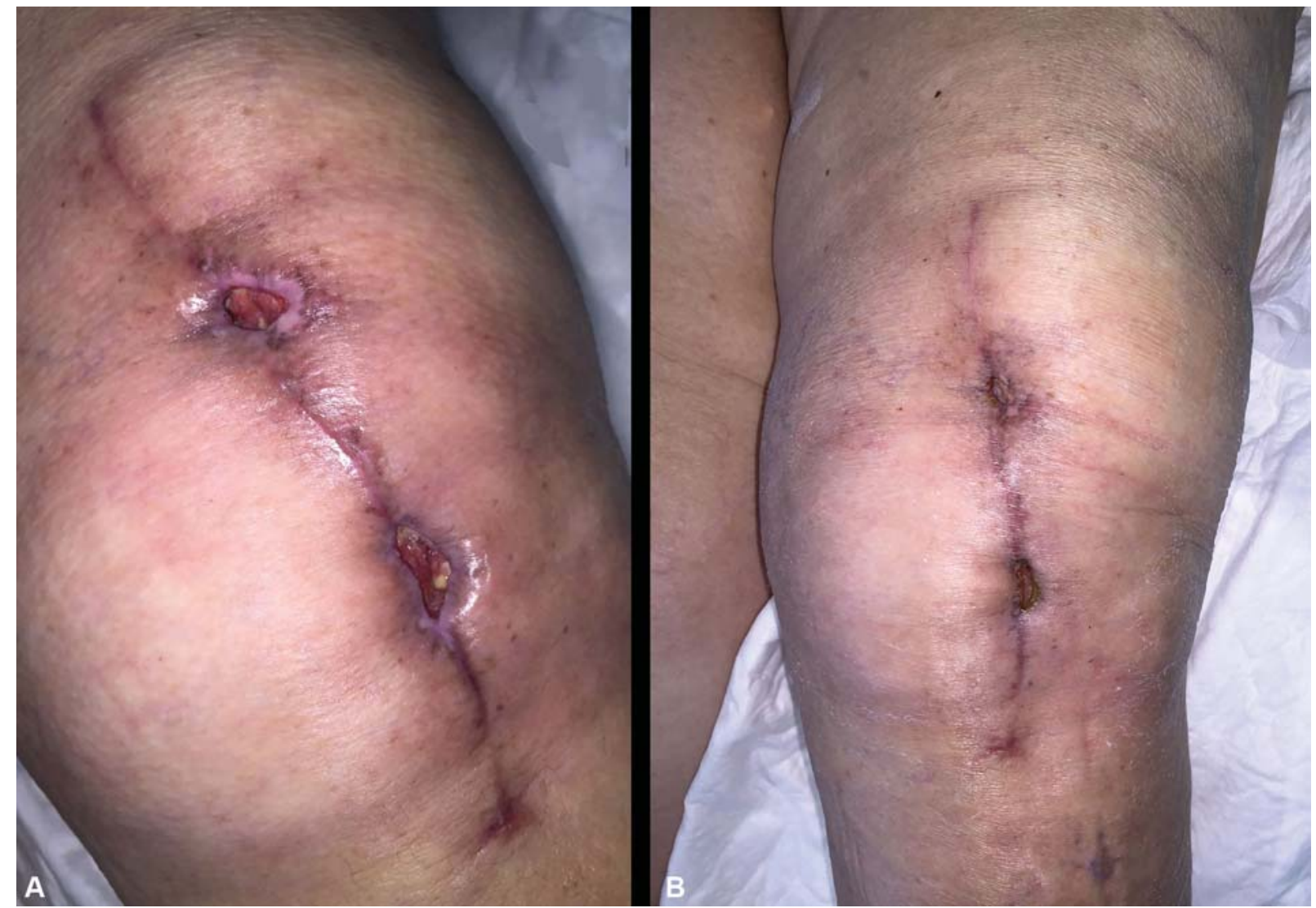

Fig. 3 Cicatrización progresiva de la herida quirúrgica a las 4 (A) y 6 semanas (B) de iniciar el tratamiento con sevoflurano.

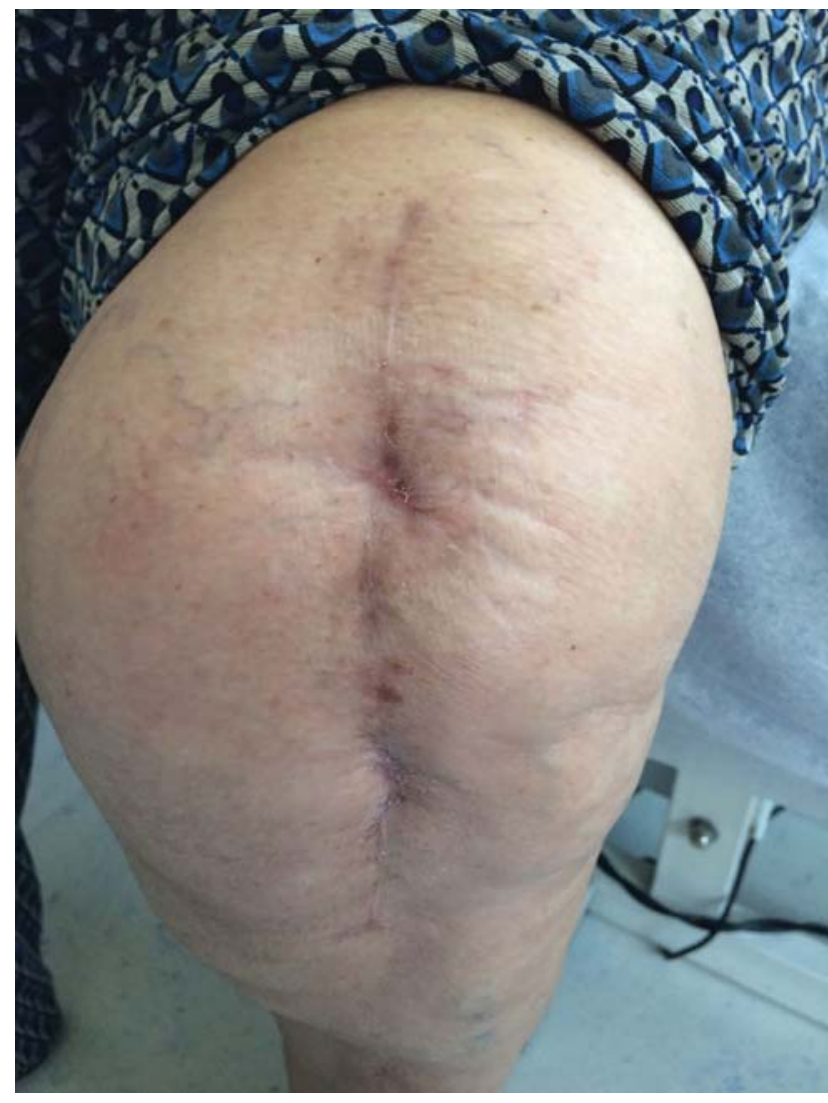

Fig. 4 Herida completamente cicatrizada.

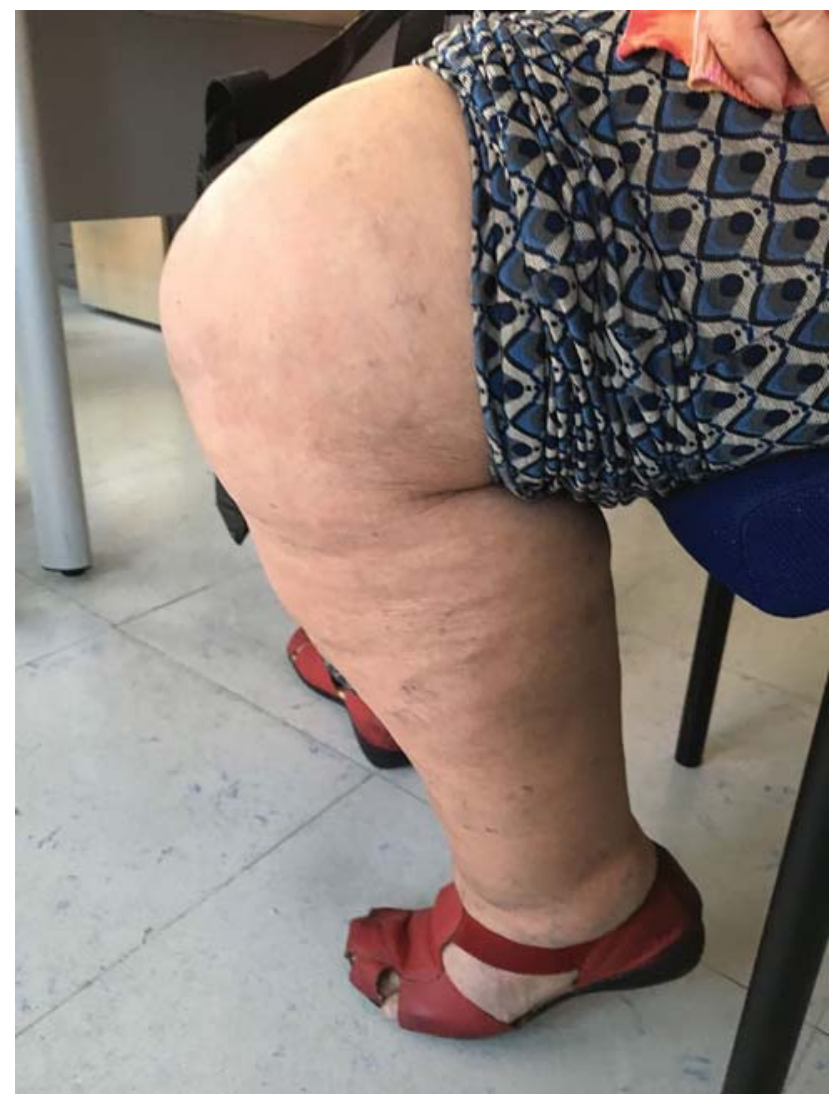

Fig. 5 Rodilla en flexión completa. 


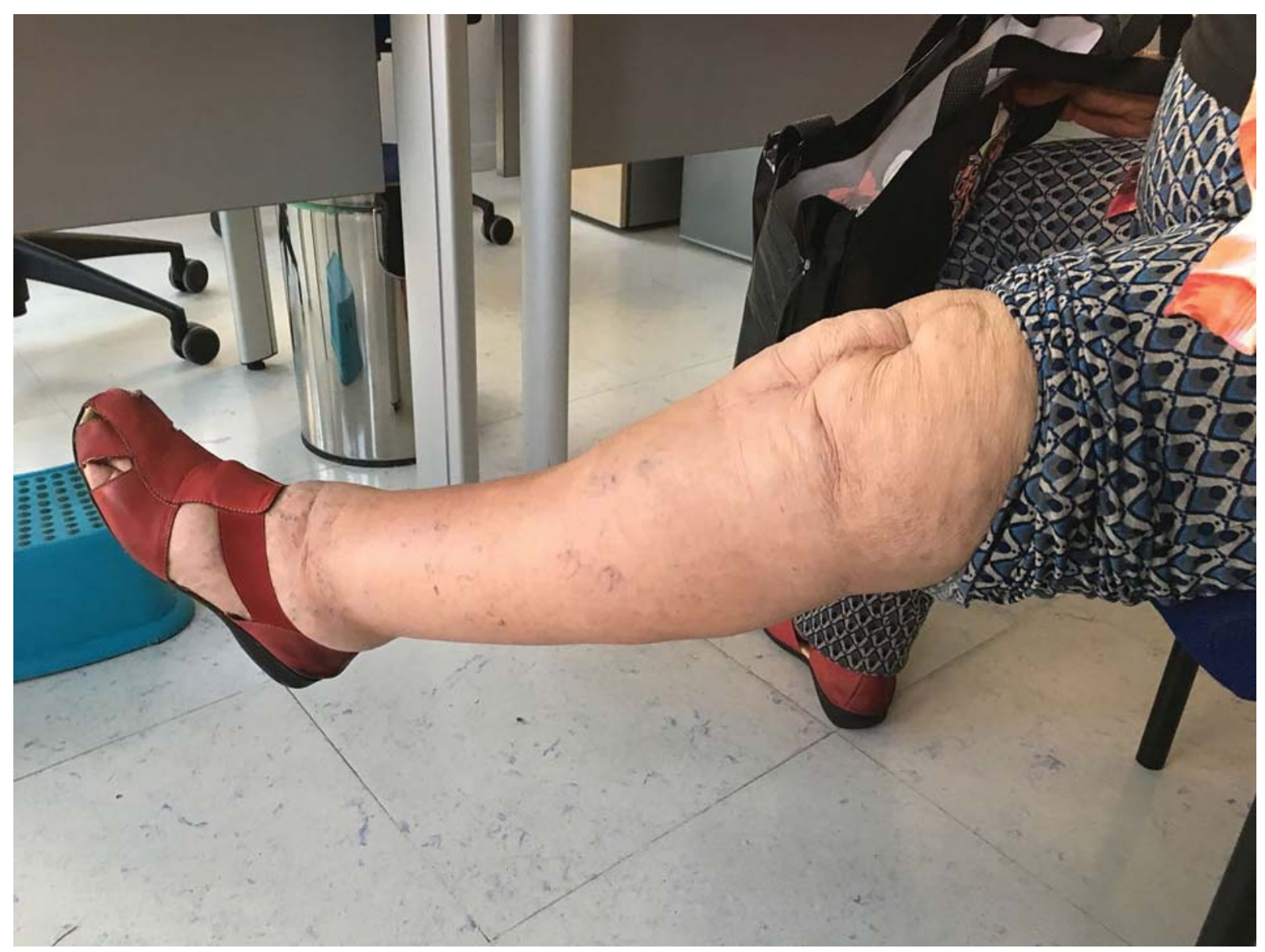

Fig. 6 Rodilla en extensión completa.

El reto principal en ese caso era establecer el diagnóstico diferencial entre una IPA y una infección de partes blandas superficial/profunda. ${ }^{8,9}$

El diagnóstico de IPA propuesto en el Segundo Consenso de Infecciones Musculoesqueléticas de 2018 pasa por la obtención de muestras de líquido sinovial. ${ }^{10}$ En nuestro caso no se realizó artrocentesis motivado por el riesgo de causar una IPA iatrogénica debido a la celulitis perilesional, y a la posibilidad de que el cultivo fuese falsamente negativo debido a la antibioterapia previa. Dado que no se obtuvo líquido sinovial, no podemos establecer un diagnóstico cierto de IPA; nuestro diagnóstico de sospecha de IPA se fundamentó en datos clínicos y analíticos (celulitis, dehiscencia y exudado purulento de la herida quirúrgica, PCR cercana a $100 \mathrm{mg} / \mathrm{L}$ ).

Pero sí que había certeza de infección de la herida quirúrgica por SARM, la cual empeoró progresivamente a pesar de ser tratada con varios tratamientos tópicos convencionales asociados a la antibioterapia empírica. Sin embargo, la evolución fue muy favorable desde el inicio de las irrigaciones de sevoflurano, con desaparición de la celulitis y mejoría de los valores de PCR a pesar de que la antibioterapia empírica se mostró ineficaz frente a SARM y de que la herida era profunda. Abundando en la capacidad antimicrobiana del sevoflurano, hay dos experiencias comunicadas en las que el sevoflurano fue eficaz en el tratamiento de infecciones estafilocócicas sobre material de osteosíntesis, y es de destacar que en ambos casos se pudieron mantener los implantes y las fracturas consolidaron, ${ }^{11,12}$ incluso cuando el agente infectante era un SARM. ${ }^{11}$ Aunque en nuestro caso no podemos afirmar que la herida quirúrgica asociara una IPA, resulta muy atractiva la idea de que las aplicaciones de sevoflurano tópico pudieran ser también útiles en el tratamiento de IPAs.

En relación al manejo antibiótico, en nuestro centro las artritis sépticas de rodilla, con o sin implante, se tratan con vancomicina $1 \mathrm{~g} / 8 \mathrm{~h}$ y ceftriaxona $2 \mathrm{~g} / 24 \mathrm{~h}$, basado en estudios de la ecología local. ${ }^{13}$ Pero esa paciente fue tratada con ciprofloxacino y rifampicina porque era alérgica a penicilinas y el tratamiento fue inicialmente ambulatorio por vía oral. Esos antibióticos son una buena combinación en el tratamiento de las infecciones estafilocócicas, ${ }^{5,7}$ que son los microorganismos más frecuentemente implicados. ${ }^{13}$

En cuanto al tratamiento quirúrgico de las IPAs, se recomienda que se realice precozmente, incluso cuando el diagnóstico sólo es de sospecha. ${ }^{2}$ Existen buenas tasas de éxito reportadas cuando el DAIR se realiza antes de las 4-6 semanas postoperatorias. ${ }^{7,14}$ En nuestro caso, aunque finalmente no se intervino por los motivos ya explicados, sí se estableció la indicación quirúrgica porque estábamos en torno al mes postoperatorio o dos semanas desde el inicio de los síntomas, según se considere. 
En cuanto al sevoflurano, esa opción terapéutica es novedosa y merece ser comentada con más detalle. El sevoflurano es un líquido volátil que es ampliamente utilizado como anestésico general inhalatorio. Sin embargo, en los últimos años se están comunicando casos clínicos y series de casos en los que el sevoflurano líquido se ha aplicado con éxito sobre heridas complicadas.

El motivo principal para emplear el sevoflurano tópico en esa paciente, fue como tratamiento antimicrobiano, y ciertamente la evolución clínica fue rápidamente favorable desde el inicio del tratamiento a pesar de que el microorganismo causante resultó ser resistente a los antibióticos empíricos pautados con los que estaba siendo tratada. Se ha propuesto que el eventual mecanismo de acción antimicrobiano del sevoflurano consistiría en la disolución de las envolturas celulares bacterianas, ya que posee propiedades disolventes. ${ }^{15} \mathrm{Si}$ eso fuese así, se mostraría eficaz frente a microorganismos resistentes a antibióticos convencionales, y de hecho existen algunas experiencias preclínicas y clínicas favorables en ese sentido. ${ }^{11,12,15-17}$ En un estudio in vitro se objetivó un rápido efecto bactericida del sevoflurano líquido frente a microorganismos tanto sensibles como resistentes a los antibióticos convencionales, en concreto un SARM, un $E$. coli BLEA, y una P.aeruginosa multirresistente. ${ }^{15}$ Clínicamente se ha mostrado eficaz como monoterapia; un absceso epidural recidivante y fistulizado a piel, causado por E.coli sensible en esa ocasión, se curó tras 8 semanas de irrigaciones ambulatorias cada 2-3 días de sevoflurano exclusivamente, y se evitó una nueva craneotomía de limpieza ${ }^{17}$; y una herida subcostal infectada por $P$. aeruginosa multirresistente en un paciente inmunodeprimido post-transplante hepático se curó tras cuatro irrigaciones semanales de sevoflurano como única alternativa terapéutica. ${ }^{16}$ También ha sido eficaz en combinación con otras terapias, como en los dos casos referidos anteriormente de infecciones estafilocócicas sobre material de osteosíntesis ${ }^{11,12}$; no obstante, es de destacar que en ambos casos las heridas mejoraron llamativamente tras la adición al tratamiento de sevoflurano líquido. Al igual que en nuestro caso, el tratamiento se realizó inyectando el sevoflurano líquido en la cámara creada tras cubrir las heridas con un plástico, lo que permite al fármaco discurrir por las anfractuosidades de las heridas.

\section{Conclusión}

El sevoflurano tópico aparece como una novedosa opción terapéutica útil para adicionar al manejo terapéutico de heridas postquirúrgicas infectadas o con sospecha de infección, especialmente cuando se pretenda intentar un tratamiento retentivo de un implante o de material de osteosíntesis y cuando la herida esté sobreinfectada por microorganismos resistentes a los antibióticos convencionales.

\section{Conflicto de Intereses}

Los autores declaran no tener ningún conflicto de intereses.

\section{Agradecimientos}

Los autores agradecemos a los Drs. Ángel Escudero Jiménez y Sergio Salmerón Ríos la ayuda prestada en el manejo de la paciente desde los puntos de vista microbiológico y clínico-geriátrico.

\section{Referencias}

1 Wouthuyzen-Bakker M, Ebied A, Hyonmin C, Shohat N, Sameh M. Parte II Cadera y Rodilla (Sección 5: Tratamiento). En: Parvizi J, Gehrke T. Segundo Consenso Internacional sobre Infecciones Musculoesqueléticas. $1^{\text {a }}$ Edición, Madrid: Editorial Imaidea Interactiva, S.L; 2018:448-450

2 Malizos K, Komnos G, Koutalos A. Parte II Cadera y Rodilla (Sección 2: Diagnóstico). En: Parvizi J, Gehrke T. Segundo Consenso Internacional sobre Infecciones Musculoesqueléticas. $1^{\text {a }}$ Edición, Madrid: Editorial Imaidea Interactiva, S.L; 2018:369-370

3 Naselli A, Accame L, Buffa P, et al. Granulated sugar for adjuvant treatment of surgical wound infection due to multi-drugresistant pathogens in a child with sarcoma: a case report and literature review. Infez Med 2017;25(04):358-361

4 Oliashirazi A, Purtill JJ, Fram B. Parte II Cadera y Rodilla (Sección 5: Tratamiento). En: Parvizi J, Gehrke T. Segundo Consenso Internacional sobre Infecciones Musculoesqueléticas. $1^{\text {a }}$ Edición, Madrid: Editorial Imaidea Interactiva, S.L; 2018:446-447

5 Simons MJ, Amin NH, Scuderi GR. Acute wound complications after total knee arthroplasty: prevention and management. J Am Acad Orthop Surg 2017;25(08):547-555

6 Guirro P, Hinarejos P, Puig-Verdie L, et al. Superficial wound infection does not cause inferior clinical outcome after TKA. Knee Surg Sports Traumatol Arthrosc 2016;24(10):3088-3095

7 Luthringer TA, Fillingham YA, Okroj K, Ward EJ, Della Valle C. Periprosthetic joint infection after hip and knee arthroplasty: A review for emergency care providers. Ann Emerg Med 2016;68 (03):324-334

8 Torres-Claramunt R, Gil-González S, Leal J, et al. A new score assessing the surgical wound of a TKA and its relation with pain, infection and functional outcome. Acta Orthop Belg 2015;81(04): 713-719

9 Allami MK, Jamil W, Fourie B, Ashton V, Gregg PJ. Superficial incisional infection in arthroplasty of the lower limb. Interobserver reliability of the current diagnostic criteria. J Bone Joint Surg Br 2005;87(09):1267-1271

10 Parvizi J, Tan TL, Goswami K, et al. The 2018 definition of periprosthetic hip and knee infection: An evidence-based and validated criteria. J Arthroplasty 2018;33(05):1309-1314.e2

11 Losa Palacios S, Achaerandio de Nova A, Gerónimo Pardo M. Manejo multimodal conservador de material de osteosíntesis ante herida quirúrgica con sobreinfección polimicrobiana, incluyendo Staphylococcus aureus resistente a meticilina. Caso clínico. Rev Esp Cir Ortop Traumatol 2020;64(02):125-129. Doi: 10.1016/j.recot.2019.11.001

12 Losa-Palacios S, Achaerandio-de Nova A, Restrepo-Pérez M, Gerónimo-Pardo M. Uncooperative patient with an infected elbow osteosynthesis: alternative management with topical sevoflurane. Wounds 2019;31(10):E68-E72

13 Achaerandio de Nova A, Losa Palacios S, Escudero Jiménez A, Blanch Sancho JJ, Gómez-Juárez Sango M, Gerónimo Pardo M. Patrón de sensibilidad de los patógenos causantes de infección osteoarticular de rodilla en Albacete. Etiología y estudio de sensibilidad. Acta Ortopédica Castellano-Manchega. 2017;17:29-34 
14 Wouthuyzen-Bakker M, Soriano A, Lange J. Parte I Asamblea General (Sección 2: Diagnóstico). En: Parvizi J, Gehrke T. Segundo Consenso Internacional sobre Infecciones Musculoesqueléticas. 1ª Edición, Madrid: Editorial Imaidea Interactiva, S.L; 2018:201-202

15 Martínez-Serrano M, Gerónimo-Pardo M, Martínez-Monsalve A, Crespo-Sánchez MD. Antibacterial effect of sevoflurane and isoflurane. Rev Esp Quimioter 2017;30(02):84-89

16 Rueda-Martínez JL, Gerónimo-Pardo M, Martínez-Monsalve A, Martínez-Serrano M. Topical sevoflurane and healing of a post- operative surgical site superinfected by multi-drug-resistant Pseudomonas aeruginosa and susceptible Staphylococcus aureus in an immunocompromised patient. Surg Infect (Larchmt) 2014;15 (06):843-846. Doi: 10.1089/sur.2013.079

17 Ferrara P, Domingo-Chiva E, Selva-Sevilla C, Campos-García J, Gerónimo-Pardo M. Irrigation with liquid sevoflurane and healing of a postoperative, recurrent epidural infection: a potential cost-saving alternative. World Neurosurg 2016;90:702. e1-702.e5. Doi: 10.1016/j.wneu.2016.02.079 